\title{
Kablosuz Algılayıcı Ağlarda Olasılıksal Kapsama Oranının Optimizasyonu için Yeni Bir Meta-Sezgisel Yaklaşım
}

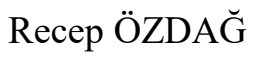 \\ Bilgisayar Mühendisliği, Yüzüncü Yıl Üniversitesi, Van, Türkiye \\ rozdag@yyu.edu.tr \\ (Geliş/Received:01.06.2017; Kabul/Accepted:08.10.2017) \\ DOI: $10.17671 /$ gazibtd. 318158
}

\begin{abstract}
$\ddot{O}_{z e t}$ - Askeri ve sivil ortamlardaki kritik bölgelerin aktif olarak gözetlenmesi bakımından ilgili alanın tümünün kapsanma oranının optimizasyonu Kablosuz Algılayıcı Ağ (KAA)'ların alandaki etkinliğini belirler. KAA'lardaki kapsama problemi alanın algılayıcı düğümler tarafından etkin olarak kapsanmasını belirleyen kritik faktörlerden biridir. Literatürde alan kapsama ve hedef kapsama olarak sınıflandırılan kapsama problemindeki amaç; tüm alanın veya alanda deterministik olarak belirlenen hedeflerin dağıtılan düğümler tarafından etkin olarak kapsanmasını sağlamaktır. Bu amaç doğrultusunda ilgili alanda algılayıcı düğümlerin optimum dinamik dağıtımları yapılarak KAA'lardaki kapsanma problemine optimum bir çözüm bulunabilir. Bu çalışmada, alan kapsama problemi dikkate alınıp mobil ve statik düğümlerden oluşan heterojen düğümler kullanılarak Olasılıksal Tarama Modeline göre ağın kapsanma oranı optimize edilmeye çalışılmıştır. Bu amaçla; meta-sezgisel olan Elektromagnetizma-Benzer (Electromagnetism-Like - EM) algoritması esas alınarak KAA'lar için yeni bir dinamik dağıtım algoritma yaklaşımı geliştirilmiştir. Bu yaklaşım literatürdeki EM algoritmasını temel alan Optimum Algılayıcı Tarama Algoritması (Optimal Sensor Detection Algorithm based on EM - OSDA-EM) ile karşılaştırılması yapılarak bu yöntemin performansı ve etkinliği ölçülmüştür. Simülasyon sonuçları; geliştirilen yöntemin tüm alanın olasılıksal kapsama probleminin çözümünde hem kapsanma oranı hem de düğümlerin yakınsama hızı açısından optimum sonuçlar verdiğini ve önerilebileceğini göstermiştir.
\end{abstract}

Anahtar Kelimeler - kablosuz algılayıcı ağlar, alan kapsama problemi, dinamik dağıtım, olasılıksal tarama modeli, elektomagnetizma-benzer algoritmas1

\section{A New Meta-Heuristic Approach for Optimization of Probabilistic Coverage Rate in Wireless Sensor Networks}

\begin{abstract}
The optimization of the coverage rate of the entire field of interest in terms of active surveillance of critical regions in military and civil environments determines the efficiency of the Wireless Sensor Networks (WSN) in the area. The coverage problem in WSNs is one of the critical factors that have determined the effective coverage of the area by the sensor nodes. The purpose in coverage problem, which is classified as area coverage and target coverage in the literature, is to ensure that the entire area or deterministically-specified targets in the area are effectively covered by the distributed nodes. In accordance with this purpose, an optimum solution can be found for the coverage problem in WSNs by performing the optimum dynamic deployments of sensor nodes in the field of interest. In this study, an attempt to optimize the coverage rate of the network was made according to the Probabilistic Detection Model using heterogeneous nodes consisting of mobile and static nodes by taking into account the area coverage problem. For this purpose, a new dynamic deployment algorithm approach was developed for WSNs based on Electromagnetism-Like (EM) algorithm which is meta-heuristic. This approach was compared with the Optimal Sensor Detection Algorithm based on EM (OSDA-EM) in the literature, and the performance and effectiveness of this method were measured. Simulation results indicated that the developed method produced optimum results in terms of coverage rate and convergence rate of the nodes in the solution of the probabilistic coverage problem of the entire area and that it could be proposed.
\end{abstract}

Keywords - wireless sensor networks, area coverage problem, dynamic deployment, probabilistic distribution model, electromagnetism-like algorithm 


\section{GİRIŞ (INTRODUCTION)}

KAA'lar askeri gözetleme [1], doğal ortamın izlenmesi [2], orman yangını tespiti [3] gibi çoğu uygulamaların ortaya çıkmasında önemli bir rol oynamaktadır. Bu tür uygulamalar için ortak olan görüş: her algılayıcı kendi algılama aralığı içerisinde meydana gelen olayları algılayabilir ve algılayıcılar işlem merkezine bu olayları iletmek için işbirliği içerisinde çalışırlar [4]. Bu uygulamalarda kabul edilebilir servis kalitesine (Quality of Service-QoS [5]) ulaşmak için yeterli derecede algılamanın sağlanması önemli bir gereksinimdir [6].

KAA'ların etkin olarak kapsanma konusu literatürde sıklıkla çalışılan problemlerin başında gelir. Algılayıcı düğümlerin deterministik veya stokastik (rastgele) dağıtıldığ 1 ilgili alanda alan kapsama (area coverage) ve hedef kapsama (target coverage) olarak kapsama problemi sınıflandırılır [7]. Alan kapsamada; dağıtılan düğümler ile alandaki her bir hedef noktasının en az bir algılayıcı düğüm tarafından kapsanıp kapsanmadığı kontrol edilirken, hedef kapsamada ise ilgili alanda deterministik olarak belirlenen hedef noktaların kapsanma durumları kontrol edilir.

KAA'ların kapsama problemlerinin çözümünde temel olan iki algılayıcı tarama modeli esas alınır. İlk model; İkili Tarama Modeli (Binary Detection Model) [8, 9]'dir. $\mathrm{Bu}$ model de algılayıcı düğüm kendi tarama yarıçapı mesafesi içerisine konumlanan bir hedefi \%100 olasılıkla algılar. Fakat bu mesafe dişındaki herhangi bir hedef noktasını ise algılamaz. $\mathrm{Bu}$ algılama modeli daha çok arazideki düğümlerin algılamalarını fiziksel olarak engelleyecek herhangi bir çevresel etkenin olmadığı ve algılayıcıların sadece kendi tarama yarıçapı içindeki tüm hedefleri mükemmel bir olasılık ile kapsadığı varsayımı üzerine çalışır. $\mathrm{Bu}$ model algılayıcıların algılama kapasitesini tümüyle kullanamayabilir. Çünkü gereğinden fazla düğümün dağıtılarak aktif olması düğümlerin enerjilerinin boşa harcanarak ağın yaşam süresinin azalmasına sebep olacaktır. İkinci model ise, Olasılıksal Tarama Modeli (Probabilistic Detection Model) [10, 11] dir. $\mathrm{Bu}$ modelde düğüm kendi merkezinden başlamak üzere belirli bir mesafeye kadar olan hedefleri çevresel etkenlerden dolayı farklı olasılıksal değerler ile algılar. Disk modeline göre hedefler daha gerçekçi bir şekilde algilanır.

$\mathrm{Bu}$ makalede, ilgili alanda başlangıçta rastgele olarak dağıtımı yapılacak olan mobil ve statik düğümlerden oluşan homojen düğüm kümesi kullanılarak Olasılıksal Tarama Modeli ile alanın kapsanma oranı optimize edilecektir. $\mathrm{Bu}$ amaçla; meta-sezgisel olan Elektromagnetizma-Benzer algoritmasinı temel alan Olasılıksal Maksimum Alan Tarama Algoritması (Probabilistic Maximum Area Detection Algorithm based on Electromagnetism-Like-PMADA-EM) geliştirilmiştir.
Bu makalede, Bölüm 2'de literatür çalışmalarına yer verilmiştir. Bölüm 3'de KAA'lardaki dinamik dağıtım problemi açıklanarak algılayıcı tarama modellerinden bahsedilmiştir. Bölüm 4'te bu çalışmadaki düğümlerin dinamik dağıtımında esas alınan EM algoritması açıklanmış ve kapsama probleminin çözümü için Olasılıksal Tarama Modeli kullanılarak geliştirilen algoritma sunulmuştur. Bölüm 5 'de ise, MATLAB ortamında elde edilen deneysel bulgular OSDA-EM ile karşılaştırılarak tartışılmış ve ulaşılan nihai sonuçlar Bölüm 6'da sunulmuştur.

\section{LITERATÜR ARAŞTIRMASI (LITERATURE RESEARCH)}

Algılayıcıların dinamik dağıtımlarının etkin olarak yapılması KAA'ların kapsama oranlarının optimizasyonunda en önemli bir faktör olduğu şimdiye kadar yapılan literatürdeki çeşitli algoritma ve yeni yaklaşım çalışmaları ile tespit edilmiştir. Çeşitli dinamik dağıtım stratejilerinden faydalanılarak alandaki algılayıcı düğümlerin dinamik dağıtımlarının yapılması bu çalışmaların ana hedefini oluşturmaktadır. Literatürde sezgisel olmayan algoritmalar kullanılarak ikili tarama modeli ile gerçekleştirilen çalışmalar [8, 12, 13, 14] mevcuttur. Bu makalede, meta-sezgisel algoritma esas alınarak alan kapsama problemine çözüm bulunacağı için bu bölümde literatürde ağırlıklı olarak çalışılan sezgisel algoritma tabanlı yeni yaklaşımlar incelenecektir. Dügümlerin hareketinden faydalanılarak yapılacak algılayıcı dağıtımı için kullanılan sezgisel algoritmalardan biri de Sanal Kuvvet Algoritması (Virtual Force Algorithm-VFA)'dır. VFA esas alınarak geliştirilen birçok yaklaşımda araştırmacılar ağın kapsanma oranını optimize etmeye çalışmışlardır. Öncelikle Zou ve ark. [15], her bir düğümün;

1. Engeller tarafindan uygulanan itme kuvveti,

2. Öncelikli kapsama alanı tarafından uygulanan çekme kuvveti (yüksek dereceli kapsamanın gerekli olduğu hassas kapsama),

3. Diğer düğümler tarafindan uygulanan itme ve çekme kuvveti,

olarak tanımlanan üç tür kuvvete maruz kaldığgnı varsayarak VFA'yı temel alan dinamik dağıtım algoritması tasarlamışlardır. VFA ile düğümlerin dağıtımında ihmal edilebilir hesaplama süresini ve yeniden konumlanmalarını içeren bir dizi avantaj elde etmişlerdir. Ayrıca önerilen Olasılıksal Konumlama Algoritmasının kuvvet yönelimli algılayıcı yerleşimi ile nasıl kullanılabileceği ve hedef tespiti için enerji tüketimini kayda değer bir şekilde azaltabileceği gösterilmiştir.

Garetto ve ark. [16], mobil düğümlerin yeniden dağıtımı problemini dikkate alarak çevresel izleme için dügüumlerin kendi kendine dağılımını ve olay tabanlı yeniden yerleşimini mümkün kılan ve VFA'yı temel alan dağıtık bir algılayıcı yaklaşımı önermişlerdir. $\mathrm{Bu}$ yaklaşımda 
fiziksel bir olgu veya çevresel felaket gibi bir olay meydana geldiğinde düğümler hedef konum çevresinde kendilerini yeniden konumlandırır. Önerilen algoritma optimum yaklaşım ile karşılaştırıldığında hem düğümlerin toplam hareketi hem de sistemin duyarlılığı açısından tatmin edici bir performans sağlamıştır.

Li ve ark. [17], Hedef İlişkili Sanal Kuvvet Algoritması (Target Involved Virtual Force Algorithm-TIVFA) tabanlı algılayıcı dağıtım optimizasyon stratejisini geliştirmişlerdir. Ayrıca algılayıcı koruması için bazı sezgisel kurallar ve geliştirilen algılayıcı sıralama algoritmasını sunmuşlardır. TIVFA kapsama ve tarama olasılığını artırmak için alanlara ve tespit edilen hedeflere göre algılayıcı ağların yapısını dinamik olarak ayarlayabilir. Yapılan deneysel çalışmalardan; TIVFA'nın algılayıcı ağlarda çoklu hedef izleme problemi için etkili bir yaklaşım olduğu ve geliştirilen algılayıcı sıralama algoritmas1 ile algılayıc1 koruma stratejisi sayesinde kuvvetli bir algılayıcı ağ oluşturabileceği sonucuna ulaşılmıştır.

Kukunuru ve ark. [18], daha iyi bir kapsama oranına ulaşmak için VFA ile Parçacık Sürü Optimizasyonu (Particle Swarm Optimization-PSO)'nu birleştirerek VFPSO algoritmasını önermişlerdir. VFPSO ile KAA'lardaki minimum sayıda algılayıcı kullanılarak kapsama probleminin optimum çözümüne ulaşmak mümkün olmuştur. Yapılan deneysel çalışmalar PSO yaklaşımının algılayıcı dağıtımının etkin kapsama problemi için etkili olduğunu ve KAA'larda yaklaşık optimum çözüm verdiğini göstermiştir. Ayrıca Yu ve ark. [19], algılayıcı düğümlerin VFA ile dağıtımı için Çifte Korelasyon Saptırma (Pair Correlation Diversion) olarak isimlendirilen yeni bir metrik ile Sanal Yay Kuvveti (Virtual Spring Force-VSF) yaklaşımını önermişlerdir.

Literatürde düğümlerin hareketliliğini sağlayarak dinamik dağıtımın yapıldığ PSO'dur. PSO üzerinde iyileştirmeler yapılarak statik ve mobil düğümlerin dağıtımının yapıldığı Paralel PSO (PPSO) [20] geliştirilmiştir. Li ve ark. [21], PSO ile uygunluk fonksiyonunda iyileştirmeler sonucunda Olasılıksal Tarama Modelini kullanarak VFA'dan daha iyi kapsama oranına ulaşılmışlardır.

Bal arıların zeki yiyecek arama davranışlarını modelleyen sezgisel bir algoritma olan Yapay Ar1 Koloni (Artifical Bee Colony-ABC) kullanılarak KAA'larda dügümlerin dinamik dağıtımları gerçekleştirilmiştir. Öztürk ve ark. [22], öncelikle mobil düğümleri kullanarak İkili Tarama Modeli ile düğümlerin kapsanma oranının optimizasyonu üzerinde çalışmışlardır. Sonrasında hem statik hem de mobil düğümler ile Olasılıksal Tarama Modelini kullanarak PSO'dan daha iyi alan kapsama oranına ulaşmışladır [23].

Literatürdeki optimizasyon algoritmalarından biri de meta-sezgisel EM [24] algoritmasıdır. Algılayıcı düğümler arasındaki mesafeyi esas alarak düğümlerin dinamik dağıtımlarını yapmak için EM algoritmasını temel alan dağıtım algoritması [9] geliştirilerek öncelikle İkili Tarama Modeline uygulanmıştır. Sonrasında ise, geliştirilen OSDA-EM [11] Olasılıksal Tarama Modeline uygulanarak hem ABC hem de PSO'ya göre ağın kapsanma oranı ve düğümlerin yakınsama hızları açısından optimum sonuçlara ulaşılmıştır.

\section{DİNAMIK DAĞITIM PROBLEMİ VE ALGILAYICI TARAMA MODELLERİ (DYNAMIC DEPLOYMENT PROBLEM AND SENSOR DETECTION MODELS)}

KAA'larda dağıtım problemi ilgili alanda başlangıçta rastgele olarak dağıtılan düğümlerin deterministik olarak istenen alana veya hedef noktasina yerleşememesinden kaynaklanmaktadır. Dağıtım probleminin çözümü düğ̈̈mlerin etkin bir şekilde dinamik dağıtımlarının yapılması ile mümkün olur. İki farklı algılayıcı tarama modellemesi esas alınarak ağın kapsanma oranının tespiti yapılabilmektedir.

\subsection{Ikili Tarama Modeli (Binary Detection Model)}

Bu modelde algılayıcı düğüm konumlandığı alandaki her bir hedef noktasını kendi tarama yarıçapı $(r)$ mesafesine göre;

1. $\% 100$ olasılık ile algılayarak o hedef noktasinda tam bir kapsama oluşturur,

2. $\% 0$ olasılık ile algılayarak o hedef noktasında hiçbir kapsama oluşturmaz.

İlgili alanda $\left(x^{i}, y^{i}\right)$ koordinatına konumlandığ varsayılan $S^{i}$ düğümü ile kapsanma durumu tespit edilecek olan $(x, y)$ koordinatındaki $P^{x y}$ hedef noktası arasındaki Öklid mesafesi $d\left(S^{i}, P^{x y}\right)=\sqrt{\left(x^{i}-x\right)^{2}+\left(y^{i}-y\right)^{2}} \quad$ eșitliğ kullanılarak hesaplanır ve $P^{x y}$ noktasının İkili Kapsanma Oranı (Binary Coverage Rate - BCR) Eş. (1) [24] ile hesaplanır.

$$
B C R^{x y}\left(S^{i}\right)= \begin{cases}1, & \text { eğer } d\left(S^{i}, P^{x y}\right) \leq r \\ 0, & \text { ĕgerd }\left(S^{i}, P^{x y}\right)>r\end{cases}
$$

\subsection{Olasilıksal Tarama Modeli (Probabilistic Detection Model)}

Bu modelde alandaki $S^{i}$ düğümü ile her bir $P^{x y}$ hedef noktası arasındaki Öklid mesafesi esas alınarak Eş. (2)’ye göre hedeflerin Olasılıksal Kapsanma Oranı (Probabilistic Coverage Rate - PCR) hesaplanır [10]. 


$$
\begin{aligned}
& P C R^{x y}\left(S^{i}\right) \\
& =\left\{\begin{array}{l}
0, \quad \text { ĕger } r+r^{e} \leq d\left(S^{i}, P^{x y}\right) \\
e^{-\lambda \alpha^{\beta}}, \text { ĕg er } r-r^{e}<d\left(S^{i}, P^{x y}\right)<r+r^{e} \\
1, \quad \text { ĕger } r-r^{e} \geq d\left(S^{i}, P^{x y}\right)
\end{array}\right.
\end{aligned}
$$

Verilen denklemde $r^{e}$ düğümlerin hatalı tarama yarıçapını, $\lambda, \beta$ ve $\alpha=d\left(S^{i}, P^{x y}\right)-\left(r-r^{e}\right)$ ise ölçüm parametrelerini temsil etmektedir. $\mathrm{Bu}$ modelde düğüm kendi tarama yarıçapı içindeki tüm hedef noktaları aynı oranda kapsamaz. Çünkü bu modelde $r^{e} \neq 0$ için düğümlerin hatalı tarama aralığı da dikkate alınarak her bir $P^{x y}$ noktasinın $P C R$ hesaplamasi yapılır. Bu modelin İkili Tarama Modelinden farkı; $S^{i}$ düğümü $P^{x y}$ noktasına göre $r-r^{e}$ ile $r+r^{e}$ aralığına yerleşmesi durumunda hesaplanacak olan $P C R$ 'ye göre bu hedefi tarar. Diğer durumlarda $S^{i}$ düğümü hedef noktasını 0 ile $\left(r-r^{e}\right)$ aralığında \%100 olasılıkla, $\left(r+r^{e}\right)$ ile $+\infty$ aralığında ise $\% 0$ olasılık ile taramaktadır (Şekil 1).

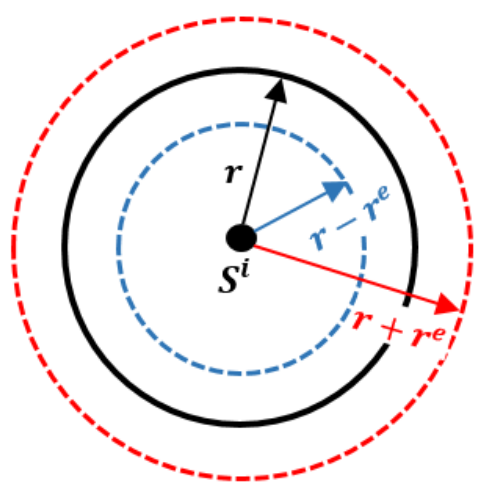

Şekil 1. $S^{i}$ düğümünün $P C R$ hesaplamasında esas alınan yarıçap mesafeleri

(Radius distances based on the PCR calculation of the $S^{i}$ node)

Bu modelde, mesela, $P_{1}^{x y}$ hedef noktası Şekil 2'de gösterilen konumda, $S^{i}$ düğümünün $r+r^{e}$ tarama aralığı ve $S^{j}$ düğümünün $r$ tarama aralığı içinde, kapsandığı varsayılsın. Bu durumda $P_{1}^{x y}$ hedefinin $P C R$ 'si Eş. (3)'e göre hesaplanır.

$$
\begin{aligned}
& P C R^{x y}\left(S^{i}, S^{j}\right) \\
& =1-\left(1-P C R^{x y}\left(S^{i}\right)\right)\left(1-P C R^{x y}\left(S^{j}\right)\right)
\end{aligned}
$$

Ayrıca, Şekil 2'de $P_{2}^{x y}$ noktasını $r$ tarama yarıçapı aralığı içinde kapsayan birden fazla düğüm olur ise bu hedef noktasında düğüm çakışması (overlap) oluşur. Bu durumda, çakışma oluşturan $n$ adet $S$ düğüm kümesi olan $S^{\text {overlap }} \subseteq\left(S^{1}, S^{2}, \ldots, S^{n}\right)$ 'in hedef noktasindaki $P C R$ 'si Eş. (4)'e göre hesaplanır [15].

$$
\begin{aligned}
& P C R^{x y}\left(S^{\text {overlap }}\right) \\
& =1-\prod_{S^{i} \in S^{\text {overlap }}}\left(1-P C R^{x y}\left(S^{i}\right)\right)
\end{aligned}
$$

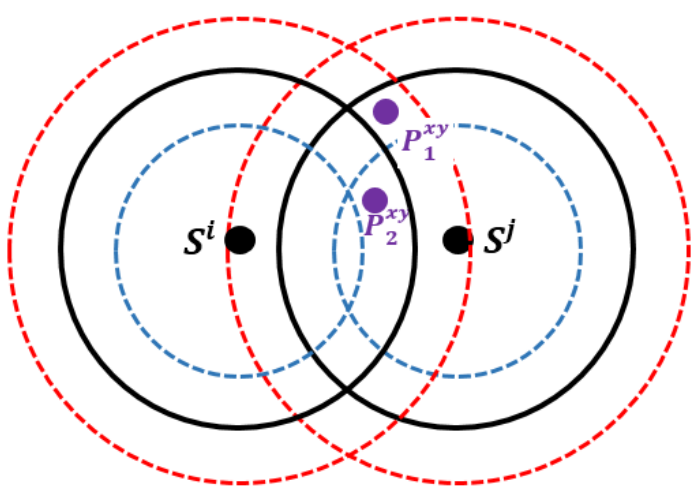

Şekil 2. $S^{i}, S^{j}$ düğümlerinin taradığı $P_{1}^{x y}, P_{2}^{x y}$ hedef noktaları ve oluşan çakışma alanı

$\left(P_{1}^{x y}, P_{2}^{x y}\right.$ destination points detectioned by nodes $S^{i}, S^{j}$ and obtained overlap area)

İlgili alandaki her bir hedef noktasının olasılıksal kapsanma oranı ağın kapsanma oranı eşik değeri $\left(c r^{t h}\right)$ parametresi ile karşılaştırılarak Eş. (5)'e göre $\forall P^{x y}$ 'nin Olasılıksal Kapsanma Durumu (Probabilistic Coverage State - PCS) hesaplanır. Böylece alandaki tüm hedeflerin $P C S$ 'si hesaplanarak alanda $c r^{\text {th }}$ 'ye göre olasılıksal olarak kapsanan hedef sayısı tespit edilir.

$$
\operatorname{PCS}\left(P^{x y}\right)=\left\{\begin{array}{lr}
1, & P C R^{x y}\left(\forall S^{i}\right) \geq c r^{t h} \\
0, & \text { aksi durumda }
\end{array}\right.
$$

\section{4. ÖNERİLEN YAKLAŞIM (PROPOSED APPROACH)}

$\mathrm{Bu}$ çalışmada, ilgili alanda rastgele olarak dağıtılan düğümlerin deterministik olarak dinamik dağıtımlarının yapılabilmesi için literatürdeki EM algoritması esas alınmıştır.

\subsection{EM Algoritmasl (EM Algorithm)}

Global optimizasyon amaciyla elektromanyetik olarak yüklü olan parçacıkların optimuma doğru hızlı bir şekilde yakınsamasını sağlayan ve bu parçacıklar arasındaki itme - çekme hareketinden esinlenerek Birbil ve Fang [24] tarafından geliştirilip modellenen meta-sezgisel [26, 27] ve popülasyon tabanlı bir algoritmadır. Doğrusal olmayan ve gerçek değerli problemlerin optimize edilmesi için tasarlanmasına rağmen sayısal problemler ile daha optimum sonuçlara ulaşılabilmiştir [28]. Çoklu nokta algoritması benzeri olan EM algoritması aynı zamanda olası bir bölgenin örnek noktalar (popülasyon) kümesi üzerinde çalışır ve elde edilen fonksiyonel değerlerin (uygunluk fonksiyonu) göreceli etkinliğine göre işler. EM algoritması çoklu arama, global optimizasyon, daha hızlı yakınsama ve eş zamanlı olarak çözüm uzayındaki noktaların çoğunu değerlendirme avantajına sahiptir [29]. EM algoritması Eş. (6)'da tanımlı olan alt ve üst sınır değişkenleri ile optimizasyon problemlerine uygulanır. 


$$
\begin{gathered}
\min f(x) \in S, \\
S=\left\{x \in \mathfrak{R}^{n} \mid \ell_{i} \leq x_{i} \leq u_{i}: l_{i}, u_{i} \in \mathfrak{R}, i\right. \\
=1,2, \ldots n\},
\end{gathered}
$$

Verilen denklemde, $n$ problemin boyutunu, $f(x)$ minimize edilecek uygunluk fonksiyonunu, $\ell_{i}$ ve $u_{i}$ çözüm uzayının alt ve sınırını, $x_{i}$ ise her bir parçacı̆̆ 1 temsil eder.

Şekil 3'de gösterilen EM algoritması tanımlama(), yerel arama(), hesaplama() ve konum değiştirme() olmak üzere 4 temel yordamdan oluşur.

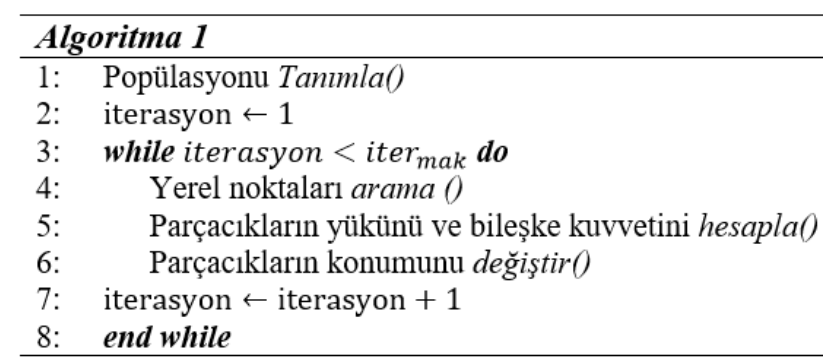

Şekil 3. EM Algoritması ve temel yordamları [24] (EM Algorithm and basic procedures)

\subsubsection{Tanımlama Yordamı (Initilization Procedure)}

$n$ boyutlu çözüm uzayında her bir $x$ örnek noktanın rastgele olarak dağıtıldığı ve örnek noktanın $f(x)$ olan uygunluk (amaç) fonksiyonunun hesaplandığı yordamdır. Eş. (6)'ya göre bir noktanın koordinatlarının çözüm uzayının üst ve alt sınırı arasında normal olarak dağıtıldığı varsayilır.

\subsubsection{Yerel Arama Yordamı (Local Search Procedure)}

$x$ örnek noktanın yerel bilgilerini toplamak amacıyla kullanıldığ 1 yordamdır. Fakat çok fazla zaman harcadığından dolayı göz ardı edilebilmektedir.

\subsubsection{Hesaplama Yordamı (Calculation Procedure)}

Çözüm uzayındaki her bir parçacık yükünün $(q)$ ve bu parçacıkların birbirine uyguladığı kuvvetlerin $(F)$ hesaplandığı yordamdır. Bir noktayı temsil eden parçacığın $q$ yük değeri onun diğer parçacıklara uygulayacağı $F$ itme ve çekme kuvvetinin büyüklüğünü belirler. Her bir örnek noktaya uygulanacak bileşke kuvvet Coulomb yasasına göre hesaplanır. Buna göre parçacıkların birbirine uygulayacağı kuvvetin büyüklüğü $q$ yükleri ile doğru orantılı, aralarındaki $d$ Öklid mesafesi ile de ters orantılı olarak değişir. Şekil 4'te gösterilen süper pozisyon ilkesine göre çözüm uzayındaki $q_{3}$ yüklü olan bir parçacığa uygulanacak olan elektromanyetik kuvvet ayrık olarak diğer parçacıkların her biri tarafından uygulanan $F_{13}$ ve $F_{23}$ kuvvetlerinin bileşkesi alınarak hesaplanır. Dolayısıyla $q_{3}$ yüklü parçacık diğer parçacıklar tarafından kendisine uygulanan itme ve çekme kuvvetlerinin bileşkesi yönünde $\left(F_{3}\right)$ hareket eder.

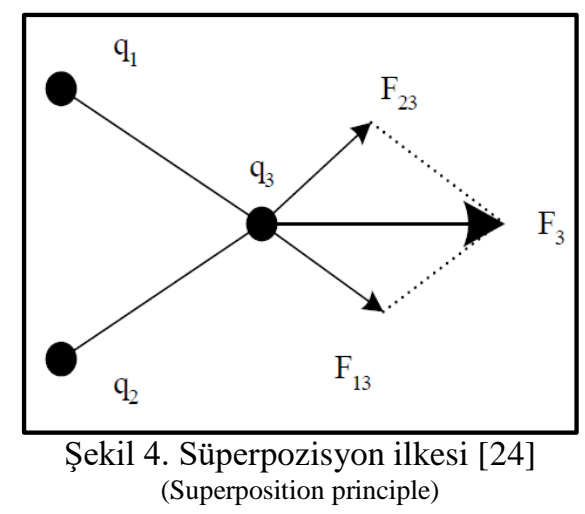

4.1.4. Konum Değiştirme Yordamı (Location Replacement
Procedure)

Optimum parçacık $f\left(x^{\text {best }}\right)$ hariç çözüm uzayındaki tüm parçacıkların bileşke kuvvet vektörü yönünde (Şekil 4) hareket ederek konumlarının değiştirildiği yordamdır. Optimum parçacık uygunluk fonksiyon değeri en iyi olan ve bu sebeple de yük değeri 1 olan parçacıktır. Dolayısıyla optimum parçacık diğer tüm parçacıkları kendisine doğru çekeceği için çözüm uzayında konumunu değiştirmez. Parçacıklar bileşke kuvvetin büyüklüğü ile orantılı olarak yer değiştirirler. Şekil 4'e göre eğer $q_{3}$ yüklü parçacığa uygulanan $F_{3}>0$ ise bu parçacık çözüm uzayında üst sınıra doğru hareket eder, aksi durumda ise alt sinıra doğru hareket ederek mevcut konumunu günceller.

\subsection{Olasilıksal Maksimum Alan Tarama Algoritması (Probabilistic Maximum Area Detection Algorithm)}

Bu makalede, KAA'nın olasılıksal kapsanma problemine çözüm bulmak için EM algoritmasındaki her parçacık ilgili alanda bir algılayıcı düğüm olarak temsil edilerek mobil düğümlerin dinamik dağıtımları yapılmıştır. İlgili alanda hem mobil hem de statik düğümler kullanılarak Olasılıksal Tarama Modeli ile ağın kapsanma oranını optimize etmek amaciyla EM algoritmasını temel alan yeni bir meta-sezgisel yaklaşım geliştirilmiştir. Geliştirilen PMADA-EM ile mobil düğümlerin etkin bir şekilde dinamik dağıtımları yapılarak ağın tanımlanan eşik değerine göre her bir hedef noktasının optimum olarak kapsanması amaçlanmıştır. $\mathrm{Bu}$ amaca ulaşmak için;

1. PMADA-EM ile her bir hedef noktasının en az bir düğüm tarafından kapsanabilmesi,

2. Aynı hedef noktalarını kapsayan düğümlerin çakışmalarını minimize etmek için bu hedeflerin daha az düğüm tarafindan kapsanabilmesi hedeflenmiştir.

Bu çalışmada, düğümler rastgele bir şekilde dağıtılarak ilgili alandaki başlangıç konumları belirlenmiştir. Statik düğümlerin mobilize özelliği olmadığg için başlangıç konumları sabitlenerek bu dügüumlere dinamik dağıtım uygulanmamıştır. Geliştirilen yaklaşımda tüm düğümlerin $f(x)$ değerleri esas alınarak sadece mobil düğümlerin 
dinamik dağıtımları yapılmıştır. Dolayısıyla mobil düğümlerin etkin dinamik dağıtımları için $f(x)$ maksimize edilerek alanda daha iyi bir çözüme doğru hareket etmeleri sağlanmıştır. Mobil düğümlerin kapsadığı hedef noktalar esas alınarak PMADA-EM'nin $f(x)$ 'i Şekil 5'deki Algoritma 2 tarafından hesaplanmıştır.

Algoritma 2'de tüm düğümlerin $f(x)$ 'leri hesaplanırken öncelikle her bir hedef noktasını $r$ tarama yarıçap mesafesi içinde kapsayan düğümler tespit edilir. Eğer hedef noktaları sadece tek bir düğüm tarafindan kapsanır ise (9. adım), bu düğümün mobil veya statik olmasına bakılmaksızın $f(x)$ güncellemesi yapılır. Hedef noktaların birden fazla düğüm tarafından kapsanması durumunda ise (11. adım), bu düğümlerin mobil veya statik olması göz önünde bulundurularak $f(x)$ hesaplaması yapılır. Eğer $P^{x y}$ hedef noktasını kapsayan düğümlerin tümü optimum olan mobil düğümlerin veya statik düğümlerin üyesi değil ise (12. adım), bu mobil dügümlerin tümünün $f(x)$ güncellemesi yapılır. $\mathrm{Bu}$ durumda, optimum olan mobil veya statik düğüm tarafindan önceden kapsanan herhangi bir hedef noktasinın tekrardan kapsanması engellenebilir. Dolayısıyla alandaki hedef noktaların gereksiz olarak birden fazla mobil düğüm tarafından kapsanmasının önüne geçilir ve kapsanmayan hedef noktaların optimum mobil düğümler ile kapsanması sağlanarak ağın kapsanma oranı optimize edilir. PMADA-EM'in Şekil 6'daki akış diyagramına göre; mobil düğümlerin başlangıç ve sonraki dağılımlarında maksimum $f(x)$ değerine ulaşan düğümler optimum mobil düğüm olarak belirlenir ve dinamik dağıtımlarda konumunun bir daha güncellenmemesi için statik düğüm olarak tanımlanır. PMADA-EM ile dağıtılan mobil dügümlerin tümü optimum oluncaya kadar veya simülasyonda tanımlı maksimum iterasyon sayısı $\left(\operatorname{Max}_{\text {iter }}\right)$ çalıştırılıncaya kadar mobil düğümlerin maksimum $f(x)$ 'e ulaşmaları sağlanmıştır (Şekil 6). Nihayetinde bu mobil düğümlerin optimum konuma hızlı bir yakınsama ile yerleşmesi sağlanarak ağın kapsanma oranı optimize edilmiştir.

Bu çalışmada, her bir simülasyonda bütün yeni değerlerin önceki elde edilen değerlerden bağımsız olarak tanımlandığı ve gerçek bir durumun stokastik modelini oluşturup, bu model üzerinden örnekleme deneyleri hazırlama tekniği olarak belirlendiği Monte Carlo metodu ile simülasyonlar $\left(M C_{\text {sim }}\right)$ yapılarak düğümlerin her bir simülasyondaki başlangıç dağglımlarının birbirinden bağımsız olması sağlanmıștır. Monte Carlo metodu ile sistemde stokastik özellik gösteren değişkenlerin olasılık dağılımları belirlenir ve daha sonra bu dağılımdan rassal sayılar aracılığı ile örnekler alınarak istenilen veriler üretilir. Böylece tanımlanan sayıda maksimum simülasyon $\left(\operatorname{Max}_{\text {sim }}\right)$ gerçekleştirilerek her simülasyonda hesaplanan kapsanma oranlarına göre ağın optimum ve ortalama kapsanma oranları tespit edilir. 


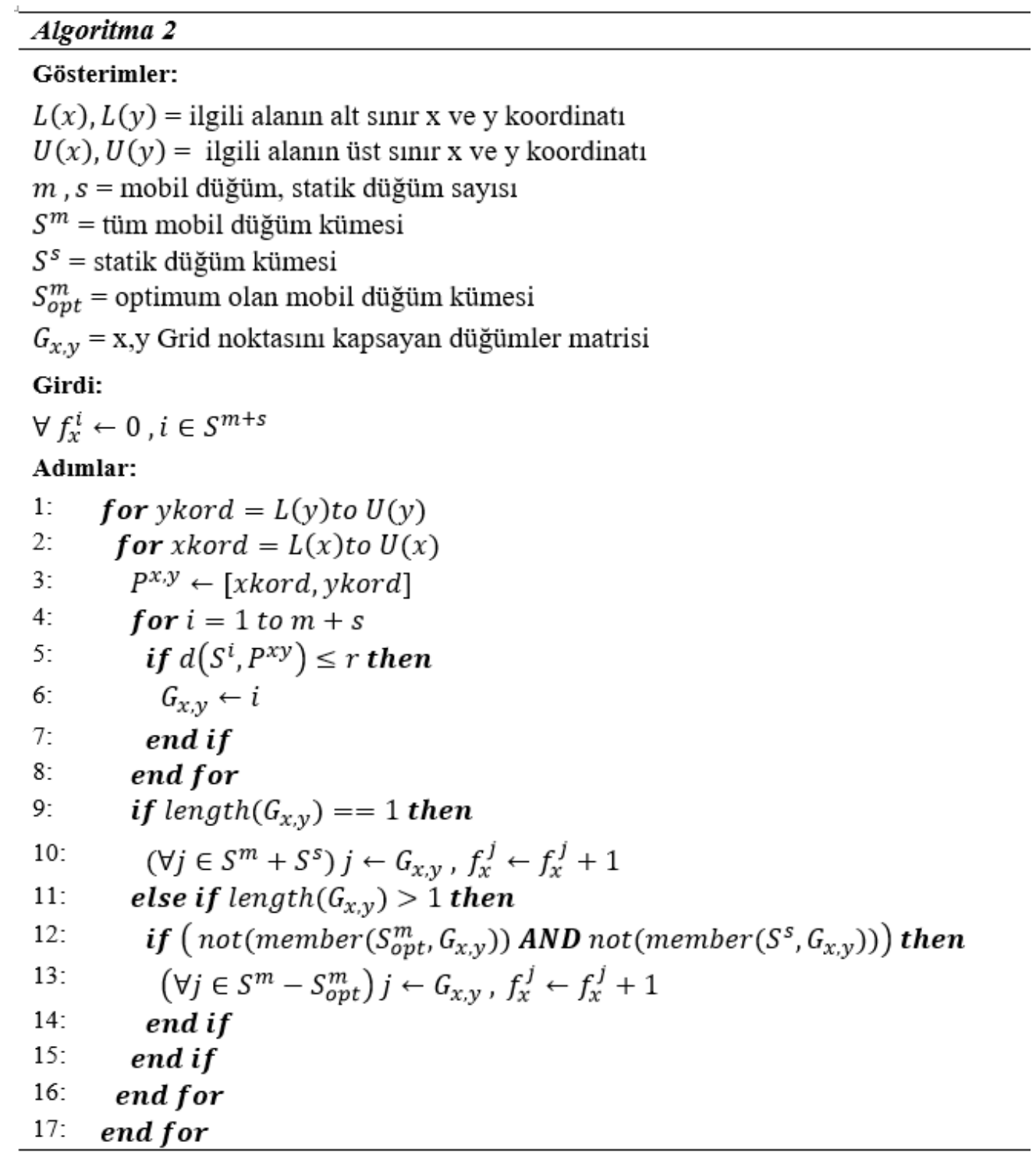

Şekil 5. PMADA-EM'nin $f(x)$ 'ini hesaplayan taslak kod (Draft code that calculates $f(x)$ of PMADA-EM) 


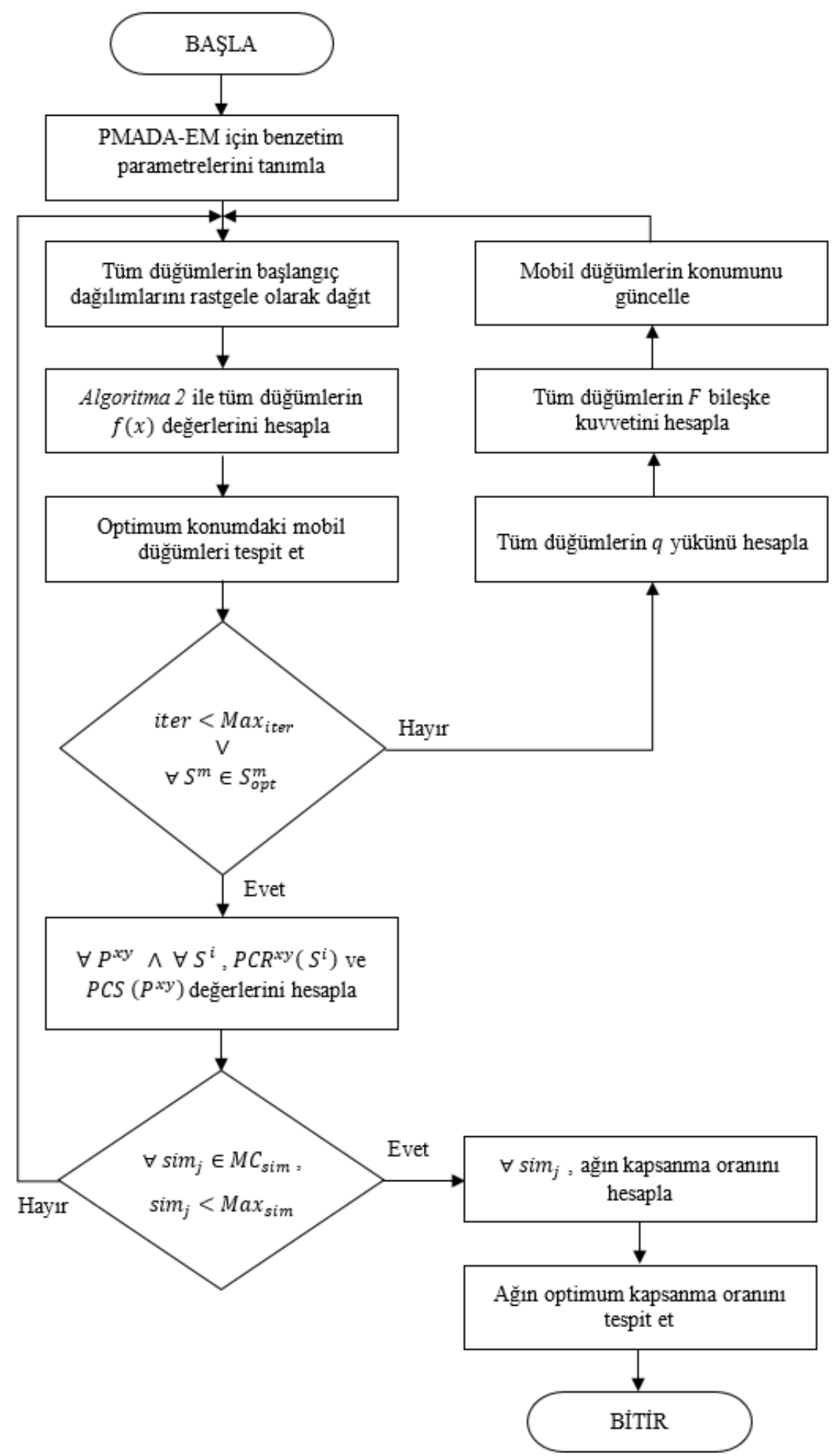

Şekil 6. PMADA-EM'in akış diyağramı (Flowchart of the PMADA-EM)

\section{DENEYSEL BULGULAR VE TARTIŞMA (EXPERIMENTAL RESULTS AND DISCUSSION)}

Bu çalışmada, geliştirilen PMADA-EM'nin simülasyonları MATLAB $^{\circledR}$ ortamında yapılarak elde edilen sonuçlar literatürdeki OSDAM-EM [11] ile karşılaştırılmıştır. Tablo 1 de gösterilen ortak parametreler kullanılarak her iki algoritmanın simülasyonları $10000 \mathrm{~m}^{2}$,den oluşan ve düğümlerin dinamik dağıtımında herhangi bir fiziksel engelin olmadığ 1 bir alanda yapıldığ 1 varsayılmıştır. Alanda dağıtılan mobil ve statik dügüum sayılarının toplamı 20 100 aralığında tanımlanmıştır. Ağın kapsama oranı hesaplanırken esas alınan eşik değerler $0,6-1$ aralığında 
tanımlanarak hedeflerin taranma olasılıkları karşılaştırılmıştır. Ayrıca her bir simülasyondaki düğümlerin başlangıç dağılımları birbirinden bağımsız olmak üzere Monte Carlo metoduna göre toplam 5 simülasyon gerçekleştirilerek algoritmalar karşılaştırılmıştır.

Hedeflerin taranma olasılığının hesaplanmasında $\lambda$ ve $\beta$ parametreleri hedeflerin optimum olarak taranmasında belirleyici bir faktör olduğu simülasyonlardan tespit edilmiştir. Şekil 7'de gösterildiği üzere düğümler hedef noktalarını $r-r^{e}(3,5 \mathrm{~m})$ mesafesine kadar \%100 olasılık ile taramaktadir. Fakat $r+r^{e}(10,5 \mathrm{~m})$ mesafesinden sonra ise $\% 0$ olasılık ile tarar. Dolayısıyla $r-r^{e}$ den $r+r^{e}$ ye kadar hedeflerin taranma olasılığı düğüm ile hedef nokta arasındaki mesafe ile ters orantılı olarak sürekli bir düşüş gözlemlenir. Şekil 7'ye göre $\lambda=0,3$ ve $\beta=0,5$ olarak tanımlandığında hedeflerin optimum taranma olasılığı ile kapsanabileceği PMADA-EM ile yapılan simülasyonlar tarafindan tespit edilmiştir. Dolayısıyla simülasyonlardaki $\lambda$ ve $\beta$ parametreleri için bu optimum değerler kullanılarak algoritmaların karşılaştırmaları yapılacaktır.
Tablo 1. Ortak simülasyon parametreleri (Common simulation parameters)

\begin{tabular}{|c|c|}
\hline Parametreler & $\begin{array}{c}\text { Tanımlandığı değer } \\
\text { veya aralık }\end{array}$ \\
\hline Ağın alan boyutu & $10000 \mathrm{~m}^{2}$ \\
\hline Toplam hedef sayısı & 10201 \\
\hline Hedefler arası mesafe & $1 \mathrm{~m}$ \\
\hline Mobil düğüm sayısı aralığı & $4-20$ \\
\hline Statik düğüm sayısı aralığı & $16-80$ \\
\hline Düğümün tarama yarıçapı & $7 \mathrm{~m}$ \\
\hline Düğümün hatalı tarama yarıçapı & $3,5 \mathrm{~m}$ \\
\hline Alfa - Beta & $0,3-0,5$ \\
\hline Ağın kapsama eşik değeri & $0,6-1,0$ \\
\hline Maksimum simülasyon sayısı & 5 \\
\hline Maksimum iterasyon sayısı & 1000 \\
\hline
\end{tabular}

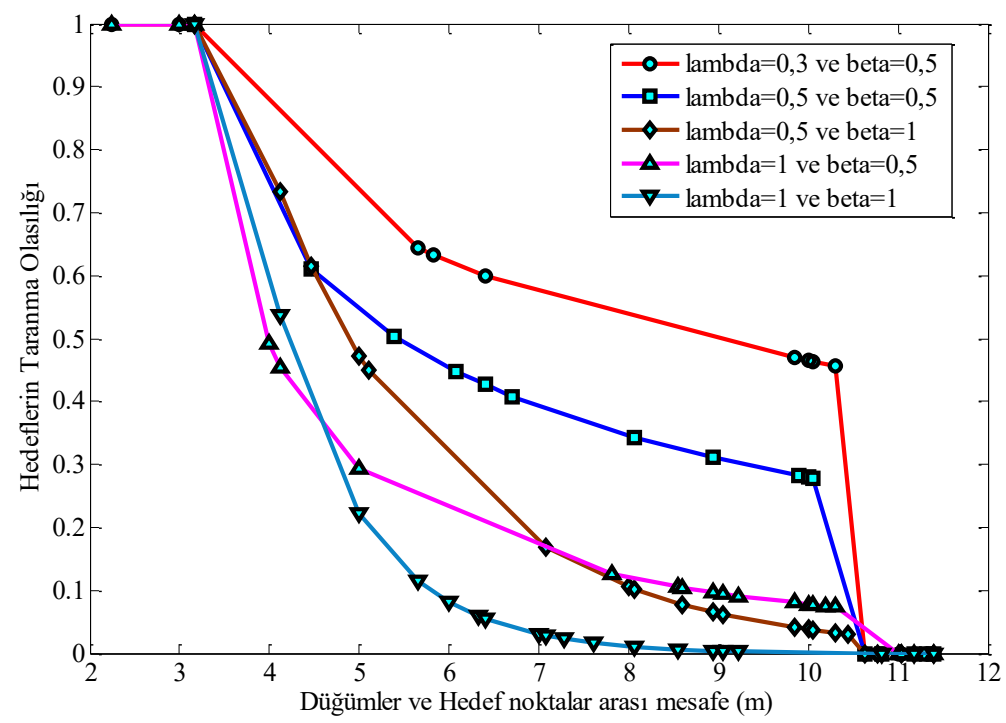

Şekil 7. Hedeflerin taranma olasılığının $\lambda$ (lamda) ve $\beta$ (beta) parametrelerine göre değişimi (Change of detection probabilities of the destinations according to $\lambda$ (lambda) and $\beta$ (beta) parameters)

Literatürdeki OSDA-EM ve geliștirilen PMADA-EM ile yapılacak düğümlerin dinamik dağıtımlarında Tablo 1'de verilen ortak parametreler tanımlanarak Tablo 2 ve Tablo 3'de tanımlanan farklı sayıdaki mobil ve statik düğümler kullanılmıştır. Her bir simülasyonda mobil düğümlerin dinamik dağıtımları maksimum 1000 iterasyona kadar yapılmıştır. Her iki algoritmada dağıtılan mobil düğümlerin tümü optimum konuma yerleştiği andan itibaren çalışan simülasyon sonlandırılarak bir sonraki bağımsız simülasyon çalıştırılmıştır. Böylece dağıtılan dügüum sayılarına göre algoritmaların simülasyonlardaki ortalama iterasyon sayısı hesaplanarak PMADA-EM ve OSDA-EM'in performansı karşılaştırılmıştır.

Toplam düğüm sayısı 20 - 100 aralığında olmak üzere; Tablo 2'de belirtilen toplam düğümlerin \%20'si mobil düğüm ve geriye kalan düğümler ise statik düğüm olarak tanımlanmıştır. Yapılan simülasyonlarda PMADA-EM ile ulaşılan ağın ortalama kapsama oranlarının, kapsama oranlarının standart sapmasının ve çalıştırılan ortalama iterasyon sayısının OSDA-EM'ye göre optimum olduğu hesaplanmıştır. PMADA-EM ile hesaplanan standart sapmanın daha düşük olması ağın kapsama oranlarının daha istikrarlı olduğunu gösterir. Ayrıca PMADA-EM ile ulaşılan ortalama iterasyon sayılarının daha düşük olması, mobil düğümlerin geliştirilen algoritma ile daha hızlı bir şekilde yakınsadığını ve optimum konuma yerleştiğini gösterir.

PMADA-EM ile yapılan dinamik dağıtımın OSDAEM'ye göre optimum olduğunu ilaveten göstermek amacıyla; Tablo 3'de belirtilen toplam dügüumlerin \%80'i 
mobil düğüm olarak tanımlanarak dinamik dağıtımları yapılmıştır. Tablo 3'deki simülasyon sonuçlarına göre; PMADA-EM ile her bir simülasyonda dağıtılan mobil düğüm sayısı Tablo 2'ye göre daha fazla olduğu için mobil düğümlerin tümünün optimum konuma yerleşmesi için çalıştırılması gereken iterasyon sayısı da fazla olacaktır. Ayrica Tablo 3'de OSDA-EM ile 80 mobil düğümün dinamik dağıtımı yapıldığında her simülasyonda 1000 iterasyon sonunda mobil düğümlerin tümü optimum konuma yerleşemediği için yapılan tüm simülasyonlar sonlandırılarak ortalama iterasyon sayısı 1000 olarak hesaplanmıştır.

Tablo 2. \%20 mobil ve \%80 statik düğümden oluşan ağda $c r^{t h}=0,6$ için PMADA-EM ve OSDA-EM tarafından yapılan dinamik dağıtımların simülasyon sonuçları

(Simulation results of dynamic deployments made by PMADA-EM and OSDA-EM for $c r^{t h}=0,6$ in a network consisting of $\% 20$ mobile and $\% 80$ static nodes)

\begin{tabular}{|c|c|c|c|c|c|c|c|}
\hline \multirow{2}{*}{\multicolumn{2}{|c|}{$\begin{array}{l}\text { Düğüm } \\
\text { Sayıları }\end{array}$}} & \multicolumn{3}{|c|}{ PMADA-EM } & \multicolumn{3}{|c|}{ OSDA-EM } \\
\hline & & \multirow{2}{*}{$\begin{array}{c}\text { Ortalama } \\
\text { Kapsama } \\
\text { Oranı }\end{array}$} & \multirow{2}{*}{$\begin{array}{c}\text { Standart } \\
\text { Sapma }\end{array}$} & \multirow{2}{*}{$\begin{array}{c}\text { Ortalama } \\
\text { iterasyon } \\
\text { saylsı }\end{array}$} & \multirow{2}{*}{$\begin{array}{c}\text { Ortalama } \\
\text { Kapsama } \\
\text { Oranı }\end{array}$} & \multirow{2}{*}{$\begin{array}{c}\text { Standart } \\
\text { Sapma }\end{array}$} & \multirow{2}{*}{$\begin{array}{c}\text { Ortalama } \\
\text { iterasyon } \\
\text { sayıs }\end{array}$} \\
\hline Mobil & Statik & & & & & & \\
\hline 4 & 16 & 26,2582 & 1,1044 & 16,20 & 26,5582 & 1,5757 & 408,60 \\
\hline 8 & 32 & 54,8436 & 1,4431 & 78,20 & 52,6654 & 2,0654 & 410,40 \\
\hline 12 & 48 & 80,5352 & 1,3771 & 158,80 & 70,9813 & 2,7918 & 415,00 \\
\hline 16 & 64 & 92,5831 & 0,8915 & 264,40 & 89,4618 & 2,1210 & 810,00 \\
\hline 20 & 80 & 97,4336 & 0,9819 & 320,00 & 95,6083 & 1,2357 & 868,00 \\
\hline
\end{tabular}

Tablo 3. \%80 mobil ve \%20 statik düğümden oluşan ağda $c r^{t h}=0,6$ için PMADA-EM ve OSDA-EM tarafından yapılan dinamik dağıtımlarda simülasyon sonuçları

(Simulation results of dynamic deployments made by PMADA-EM and OSDA-EM for $c r^{\text {th }}=0,6$ in a network consisting of $\% 80$ mobile and $\% 20$ static nodes)

\begin{tabular}{|c|c|c|c|c|c|c|c|}
\hline \multirow{2}{*}{\multicolumn{2}{|c|}{$\begin{array}{l}\text { Düğüm } \\
\text { Sayıları }\end{array}$}} & \multicolumn{3}{|c|}{ PMADA-EM } & \multicolumn{3}{|c|}{ OSDA-EM } \\
\hline & & \multirow{2}{*}{$\begin{array}{c}\text { Ortalama } \\
\text { Kapsama } \\
\text { Oranı }\end{array}$} & \multirow{2}{*}{$\begin{array}{c}\text { Standart } \\
\text { Sapma }\end{array}$} & \multirow{2}{*}{$\begin{array}{c}\text { Ortalama } \\
\text { iterasyon } \\
\text { saylsi }\end{array}$} & \multirow{2}{*}{$\begin{array}{c}\text { Ortalama } \\
\text { Kapsama } \\
\text { Oranı }\end{array}$} & \multirow{2}{*}{$\begin{array}{c}\text { Standart } \\
\text { Sapma }\end{array}$} & \multirow{2}{*}{$\begin{array}{c}\text { Ortalama } \\
\text { iterasyon } \\
\text { sayısı }\end{array}$} \\
\hline Mobil & Statik & & & & & & \\
\hline 16 & 4 & 29,2638 & 0,6593 & 51,00 & 26,4543 & 1,3170 & 423,80 \\
\hline 32 & 8 & 66,1523 & 0,7165 & 198,00 & 54,9652 & 2,3551 & 608,40 \\
\hline 48 & 12 & 90,5225 & 0,7187 & 356,60 & 76,3278 & 2,8164 & 622,40 \\
\hline 64 & 16 & 97,5493 & 0,3680 & 475,20 & 96,1023 & 1,5997 & 892,60 \\
\hline 80 & 20 & 99,4785 & 0,2100 & 552,00 & 99,1569 & 0,2275 & 1000 \\
\hline
\end{tabular}

İlgili alanda toplam $20-100$ aralığında dağıtılan düğümlerin \%80’i mobil düğüm olarak tanımlandığında PMADA-EM ile hesaplanan kapsanma oranının farklı oranlarda dinamik dağıtım yapan PMADA-EM ve OSDA-EM'ye göre optimum olduğu Şekil 8 ile tespit edilmiştir. Ayrıca PMADA-EM ve OSDA-EM'in aynı oranlarda mobil düğümlerin dinamik dağıtımları yapılarak kapsanan alanlar karşılaştırıldığında (sürekli ve kesik olan mavi ve kırmızı doğrularının kendi aralarında karşılaştırılması) PMADA-EM'in OSDA-EM'den daha optimum olduğu tespit edilmiştir.

Ortalama iterasyon sayısına göre ulaşılan ortalama kapsanma oranları Şekil 9'da karşılaştırılmıştır. Mobil düğümlerin dağıtım oranları fark etmeksizin PMADAEM ile yapılan dinamik dağıtımda düğümlerin OSDAEM'ye göre daima daha hızlı yakınsadığı simülasyonlarda hesaplanarak Şekil 9'da gösterilmiştir.
$\mathrm{Bu}$ makalede, algoritmalar için tanımlanan eşik değerlerine göre $\% 20$ - \%80 oranında dağıtılan düğümler ile yapılan simülasyonlarda hesaplanan kapsama oranları Tablo 4'te gösterilmiştir. Bu sonuçlara göre; 0,5 - 1 arasındaki eşik değerleri esas alınarak \%20 ile \%80’i mobil olarak dağıtılan 100 düğümün alanın olasılıksal kapsanma oranına olan etkisi incelendiğinde aralıktaki tüm eşik değerleri için geliştirilen PMADA-EM ile daha optimum kapsanma oranlarına ulaşılarak OSDA-EM'ye göre daha etkin dinamik dağıtım yaptığı gözlemlenmiştir. Ayrıca ağın 0,8 ile 0,9 eşik değerlerine göre dağıtılan mobil ve statik düğümler ile alanın kapsanma oranları karşılaştırıldı ğında PMADA-EM tarafından hesaplanan ortalama kapsama oranında $\% 5-\% 10$ aralığında bir artış olduğu tespit edilmiştir. 


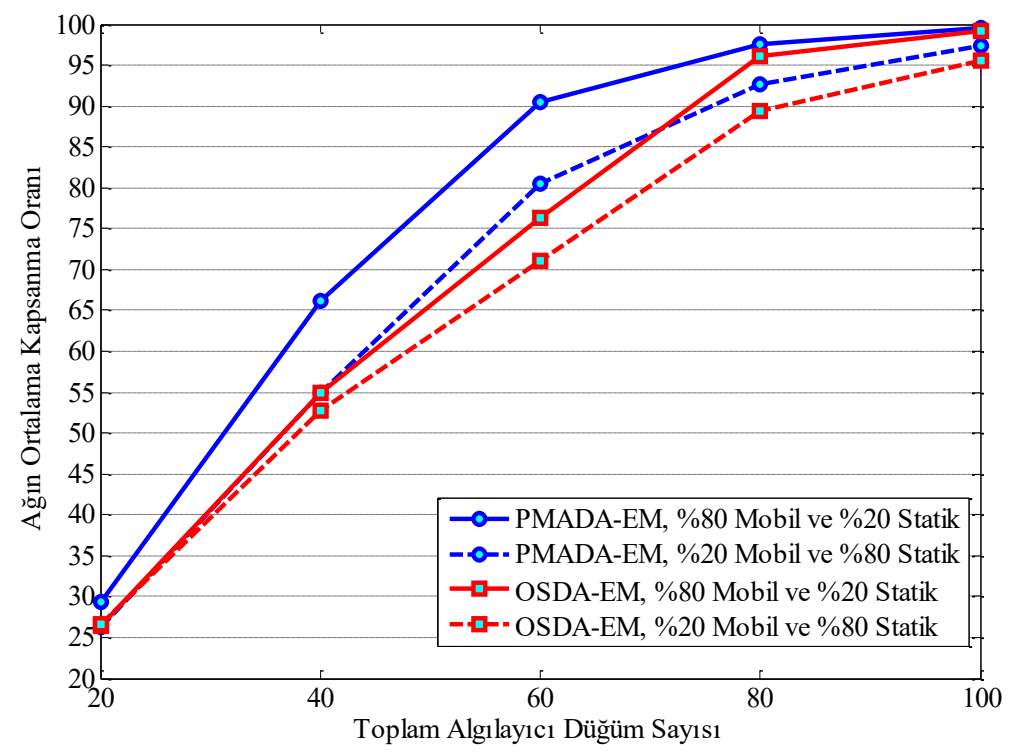

Şekil 8. PMADA-EM ve OSDA-EM ile \%20 ve \%80 oranında dağıtılan mobil-statik düğüm sayılarına göre $c^{\text {th }}=0,6$ için ağda ulaşılan ortalama kapsama oranlarının karşılaştııılması

(Comparing of the average coverage ratios achieved in the network for $c r^{t h}=0,6$ according to mobile-static node numbers distributed at $\% 20$ and $\% 80$ with PMADA-EM and OSDA-EM)

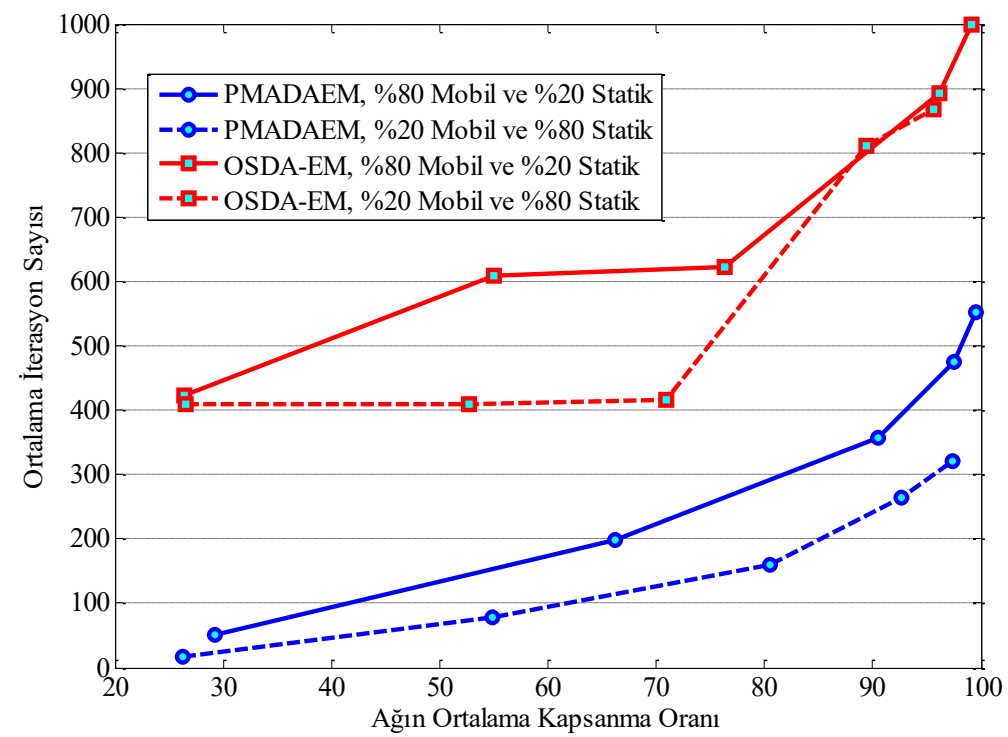

Şekil 9. PMADA-EM ve OSDA-EM tarafından \%20 ile \%80 oranında dağıtılan mobil-statik düğüm sayılarına ve ortalama iterasyon sayısına göre $c r^{t h}=0,6$ için ağda ulaşılan ortalama kapsama oranlarının karşılaştırılması

(Comparing of the average coverage rates achieved in the network for $c r^{\text {th }}=0,6$ according to average number of iterations and mobile-static node numbers distributed at $\% 20$ with $\% 80$ by PMADA-EM and OSDA-EM)

Tablo 4. 0,5 - 1 arasındaki eşik değerlerine ve $\% 20$ ile $\% 80$ oranında dağıtılan mobil ve statik düğüm sayılarına göre PMADA-EM ve OSDA-EM tarafindan hesaplanan ortalama kapsama oranları (Average coverage ratios calculated by PMADA-EM and OSDA-EM according to mobile and static node numbers distributed at $\% 20$ with $\% 80$ and threshold values between $0,5-1$ )

\begin{tabular}{|c|c|c|c|c|}
\hline \multirow{2}{*}{\begin{tabular}{c} 
cr $^{\text {th }}$ (Eşik değeri) \\
\cline { 2 - 5 }
\end{tabular}} & $\begin{array}{c}\text { 20 mobil } \\
80 \text { statik }\end{array}$ & $\begin{array}{c}\text { 80 mobil } \\
20 \text { statik }\end{array}$ & $\begin{array}{c}20 \text { mobil } \\
80 \text { statik }\end{array}$ & $\begin{array}{c}\text { 80 mobil } \\
20 \text { statik }\end{array}$ \\
\cline { 2 - 5 } & \multicolumn{4}{|c|}{ Ortalama Kapsama Oranlarl (\%) } \\
\hline $0,5(\% 50)$ & 99,1099 & 99,9216 & 98,1825 & 99,9392 \\
\hline $0,6(\% 60)$ & 97,4336 & 99,4785 & 95,4377 & 99,1589 \\
\hline $0,7(\% 70)$ & 95,5847 & 98,6707 & 92,9085 & 97,9982 \\
\hline $0,8(\% 80)$ & 89,7755 & 96,6964 & 83,9486 & 93,9006 \\
\hline $0,9(\% 90)$ & 73,5065 & 86,3229 & 68,9030 & 76,9552 \\
\hline $1(\% 100)$ & 31,7341 & 34,3398 & 30,7205 & 30,9989 \\
\hline
\end{tabular}


İlgili alandaki tüm alanın 0,5 - 1 arasındaki eşik değerlerine göre hesaplanan ortalama kapsanma oranlarının değişim grafiği Şekil 10'da gösterilmiştir. Bu grafikte, algoritmalar tarafindan $\% 20$ ile $\% 80$ oranında dinamik dağıtımı yapılan mobil düğüm parametrelerinin her birisi (düz ve kesik olan mavi - kırmızı doğrular) kendi içinde karşılaştırıldığında PMADA-EM ile daha optimum sonuçlara ulaşılabildiği görülmektedir. 0,5 'den daha düşük eşik değerlerindeki alanın olasılıksal kapsanma oranları her iki algoritma için \%99'un üzerinde hesaplanacağı için ayrıca değerlendirmeye gerek görülmemiştir.

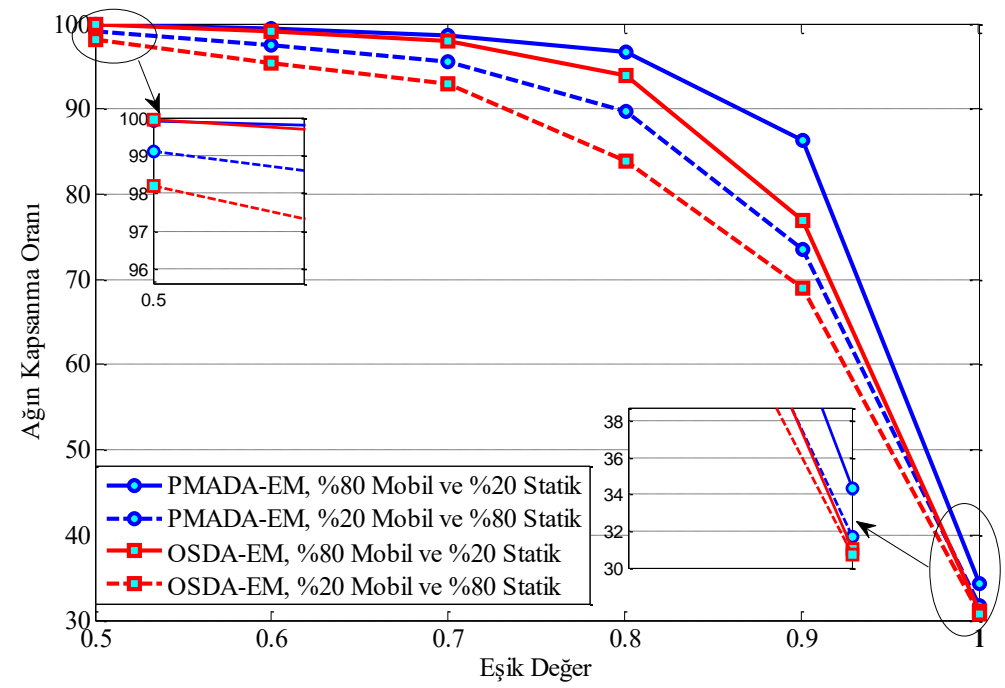

Şekil 10. 0,5 - 1 arasındaki eşik değerlerine ve $\% 20$ - \%80 oranında dağıtılan mobil ve statik düğüm sayılarına göre PMADA-EM ve OSDA-EM'nin ortalama kapsama oranlarının değişim grafiği (Change graph of the average coverage ratios of PMADA-EM and OSDA-EM according to mobile and static node numbers distributed at $\% 20-\% 80$ and threshold values between $0,5-1,0$ )

\section{SONUÇ (CONCLUSION)}

$\mathrm{Bu}$ çalışmada, 0,5 - 1 aralığındaki eşik değerlere göre ilgili tüm alanın olasılıksal kapsanma oranını optimize etmek amacıyla PMADA-EM geliştirilmiştir. PMADAEM tarafindan başlangıçta 20-100 aralığında rastgele dağıtılan düğüm sayılarına göre sirasıyla $\% 20$ ve $\% 80$ oranında mobil düğümlerin dinamik dağıtımı yapılarak literatürdeki OSDA-EM ile karşılaştırılması yapılmıştır. PMADA-EM tarafından 0,6 eşik değeri esas alınarak 48 statik düğüme karşı 12 mobil dügümün dinamik dağıtımı yapıldığında \%10'luk, 12 statik düğüme karşı 48 mobil dügüumün dinamik dağıtımı yapıldığında ise \%14'lük ortalama kapsanma oranında optimum artış olduğu tespit edilmiştir. PMADA-EM tarafindan hem $\% 20$ hem de $\% 80$ oranında mobil düğüm dağıtıldığında bu dügüülerin optimum konuma yerleşirken çalıştırılan ortalama iterasyon sayısı OSDA-EM'ye göre daima minimum olarak hesaplanmıştır. Ayrıca 0,5 - 1 aralığındaki eşik değerler esas alınarak PMADA-EM tarafindan düğümlerin $\% 20$ ve $\% 80$ oranlarında mobil olarak dinamik dağıtımları yapıldığında OSDA-EM'ye göre daima optimum kapsanma oranlarına ulaşılmıştır. Dolayısıyla Monte Carlo metodu kullanılarak yapılan simülasyonlarda geliştirilen PMADA-EM ile daha az iterasyon yapılarak minimum standart sapma üzerinden optimum kapsama oranlarına ulaşıldığı ve bu süreçte OSDA-EM'ye göre mobil düğümlerin ilgili alana daha hızlı bir şekilde yerleştiği tespit edilmiştir. Sonuç olarak, ilgili alanın hem istikrarlı bir şekilde olasılıksal kapsanma oranlarının hesaplanmasında hem de düğümlerin optimum konuma yerleşirken yakınsama hızlarının hesaplanmasinda PMADA-EM ile daha optimum sonuçlara ulaşılmıştır. Dolayısıyla PMADA-EM alanın tümünün olasılıksal olarak kapsanmasında yeni bir metasezgisel yaklaşım olarak önerilmektedir. Sonraki çalışmada düğümlerin enerji tüketimlerini optimize ederek bu yöntemin yakınsamasının optimizasyonu üzerinde çalışılacaktır.

\section{KAYNAKLAR (REFERENCES)}

[1] T. He, S. Krishnamurthy, J. A. Stankovic, T. Abdelzaher, L. Luo, R. Stoleru, T. Yan, L. Gu, J. Hui, B. Krogh, "Energy-Efficient Surveillance System Using Wireless Sensor Networks", 2nd International Conference on Mobile systems, applications and services, Boston, MA, USA, 270-283, 06-09 July, 2004.

[2] A. Mainwaring, J. Polastre, R. Szewczyk, D. Culler, J. Anderson, "Wireless Sensor Networks for Habitat Monitoring", 1st ACM International Workshop on Wireless Sensor Networks and Applications, Atlanta, Georgia, USA, 88-97, 28 September, 2002.

[3] I. F. Akyildiz, W. Su, Y. Sankarasubramaniam, E. Cayirci, "Wireless sensor networks: a survey", Computer Networks, 38 (4), 393422, 2002.

[4] M. Hefeeda, H. Ahmadi, "A Probabilistic Coverage Protocol for Wireless Sensor Networks", IEEE International Conference on Network Protocols, Beijing, China, 41-50, 16-19 October, 2007.

[5] B. Tavli, Protocol Architectures for Energy Efficient Real-Time Data Communications in Mobile Ad Hoc Networks, Doktora Tezi, University of Rochester, The College School of Engineering and Applied Sciences, 2005 
[6] J. Zhang, T. Yan, S. H. Son, "Deployment Strategies for Differentiated Detection in Wireless Sensor Networks", 3th Annual IEEE Communications Society Conference on Sensor, Mesh and Ad-Hoc Communications and Networks, Reston, VA, USA, 316-325, 28 September, 2006.

[7] B. Wang, "Coverage problems in sensor networks: A Survey", $A C M$ Computing Surveys, , 43 (4), 53 pages, 2011.

[8] K. Chakrabarty, S. S. Iyengar, H. Qi, E. Cho, "Grid Coverage for Surveillance and Target Location in Distributed Sensor Networks", IEEE Transactions on Computers, 51(12), 1448-1453, 2002.

[9] R. Özdağ, A. Karc1, "Sensor Node Deployment Based on Electromagnetism-Like Algorithm in Mobile Wireless Senso Networks", International Journal of Distributed Sensor Networks, 11(2), 15 pages, 2015.

[10] N. Ahmed, S. S. Kanhere, S. Jha, "Probabilistic Coverage in Wireless Sensor Networks", IEEE 30th Anniversary Conference on Local Computer Networks, Sydney, NSW, Australia, 672-681, 17 November, 2005.

[11] R. Özdă̆, A. Karc1, "Probabilistic Dynamic Distribution of Wireless Sensor Networks with Improved Distribution Method based on Electromagnetism-Like Algorithm”, Measurement, 79, 66-76, 2016.

[12] V. Isler, S. Kannan, K. Daniilidis, "Sampling Based Sensor Network Deployment", EEE/RSJ International Conference on Intelligent Robots and Systems, Sendai, Japan, 1780-1785, 28 September - 2 October, 2004

[13] K. Kar and S. Banerjee, "Node placement for connected coverage in sensor networks", Workshop on Modeling and Optimization in Mobile, Ad Hoc and Wireless Networks, Sophia Antipolis, France, 2 pages, March, 2003.

[14] S. Shakkottai, S. Srikant, N. Shroff, "Unreliable Sensor Grids: Coverage, Connectivity and Diameter", Twenty-second Annual Join Conference of the IEEE Computer and Communications Societies, San Francisco, CA, USA, 1073-1083, 30 March-3 April, 2003.

[15] Y. Zou, K. Chakrabarty, "Sensor deployment and target localization based on virtual forces", Twenty-second Annual Joint Conference of the IEEE Computer and Communications Societies, San Francisco, CA, USA, 1293-1303, 30 March-3 April, 2003.

[16] M. Garetto, M. Gribaudo, C. F. Chiasserini, E. Leonardi, "A distributed sensor relocation scheme for environmental control", IEEE International Conference on Mobile Adhoc and Sensor Systems, Pisa, Italy, 1-10, 8-11 October, 2007.

[17] S. Li, C. Xu, W. Pan, Y. Pan, "Sensor deployment optimization for detecting manoeuvring targets", 7th International Conference on Information Fusion, Philadelphia, PA, USA, 1629-1635, 25-28 July, 2005.
[18] N. Kukunuru, B. R. Thella, R. L. Davuluri, "Sensor deployment using particle swarm optimization", International Journal of Engineering Science and Technology, 2(10), 5395-5401, 2010.

[19] X. Yu, N. Liu, X. Qian, T. Zhang, “A Deployment Method Based on Spring Force in Wireless Robot Sensor Networks", International Journal of Advanced Robotic Systems, 11(5), 79-90, 2014.

[20] X. Wang, S. Wang, J. Ma, "Dynamic Deployment Optimization in Wireless Sensor Networks", Lecture Notes in Control and Information Sciences, 344, 182-187, 2006.

[21] Z. Li, L. Lei, "Sensor Node Deployment in Wireless Sensor Networks Based on Improved Particle Swarm Optimization", IEEE International Conference on Applied Superconductivity and Electromagnetic Devices, Chengdu, China, 215-217, 25-27 September, 2009.

[22] C. Ozturk, D. Karaboga, B. Gorkemli, "Artificial bee colony algorithm for dynamic deployment of wireless sensor networks", Turk $J$ Elec Eng \& Comp Sci, 20(2), 255-262, 2012.

[23] C. Ozturk, D. Karaboga, B. Gorkemli, "Probabilistic Dynamic Deployment of Wireless Sensor Networks by Artificial Bee Colony Algorithm", sensors, 11(6), 6056-6065, 2011.

[24] S. I. Birbil, S. C. Fang, "An Electromagnetism-like Mechanism for Global Optimization", Journal of Global Optimization, 25(3), 263282,2003

[25] R. Özdağ, "Kablosuz Algılayıcı Ağlarda Alan Kapsama için Dinamik Düğüm Dağııımı ile Yeni bir Meta-sezgisel Yaklaşım”, 4th International Symposium On Innovative Technologies in Engineering and Science, Alanya, Antalya, Türkiye, 1513-1522, 3-5 Kasım, 2016.

[26] M. Canayaz, A. Karc1, "Cricket behaviour-based evolutionary computation technique in solving engineering optimization problems", Applied Intelligence, 44(2), 362-376, 2016.

[27] M. Demir, A. Karc1, "Data Clustering on Breast Cancer Data Using Firefly Algorithm with Golden Ratio Method", Advances in Electrical and Computer Engineering, 15(2), 75-84, 2015.

[28] J. Kratica, "An Electromagnetism-Like Approach for Solving the Low Autocorrelation Binary Sequence Problem", Int J Comput Commun, 7(4), 688-695, 2012.

[29] P. Wu, W.H. Yang, N.C. Wei, "An Electromagnetism Algorithm of Neural Network Analysis -An Application to Textile Retail Operation", Journal of the Chinese Institute of Industrial Engineers, 21(1), 59-67, 2004. 